\title{
Coordination in Markets with Consumption Externalities: Advertising and Product Quality
}

Ivan Pastine

University College Dublin

School of Economics

John Henry Newman Building

Belfield, Dublin 4

Ireland

tel:353-1-7168595

fax:353-1-2830068

e-mail: ivan.pastine@ucd.ie
Tuvana Pastine

National University of Ireland Maynooth

Department of Economics

Maynooth

Co. Kildare

Ireland

tel: $353-1-7083728$

fax: 353-1-7083934

e-mail: tuvana.pastine@nuim.ie

February 2008

\begin{abstract}
This paper studies advertising in markets with positive consumption externalities. In such markets, we show that firms may engage in advertising competition to coordinate consumer expectations on their own brand as long as they produce goods of similar quality. The firm with the lower quality product has a greater incentive to advertise. Hence in equilibrium, the lower quality product will often be more popular.
\end{abstract}

We would like to thank James Albrecht and Curtis Taylor for their comments on a paper we presented at the North American Winter Meetings of the Econometric Society in Washington, D.C.. This paper is a direct result of the issues they raised. We would also like to acknowledge the assistance and advice of Neil Arnwine. All errors are of course our own. 


\section{INTRODUCTION}

This paper studies advertising in markets with positive consumption externalities. In markets with consumption externalities, the value of the product to the consumer does not only depend on the characteristics of the product but it also depends on the purchasing decisions of other consumers either due to social interaction or due to network externalities. Reading a best seller gives the additional pleasure of having common conversation topics with other people. The decision about which software to purchase is probably not only determined by the relative prices or qualities of the competing packages. The choice also involves the expectations about which one of the software packages is going to be more widely adopted. The widely adopted packages have a greater selection of compatible products developed. The users of popular systems have more people around that can help with trouble shooting.

In such markets, Pastine and Pastine (2002) show that the firm has incentives to advertise to convince consumers that its brand will be the popular one. When a consumer observes an expensive advertising campaign, he realizes that the firm would not have advertised if it did not expect advertising to increase its sales. Hence it is in the best interest of the individual to purchase the heavily advertised brand, vindicating the advertising investment of the firm. Clark and Horstmann (2005) show that this form of advertising survives even when advertising expenditure is imperfectly observable.

Pastine and Pastine (2002) analyze a market with homogenous products and Clark and Horstmann (2005) have horizontally differentiated products. In this paper, we allow for vertically differentiated products. We investigate whether advertising can serve a coordinating function when goods are of different qualities. We then examine the nature of the advertising competition. We show that firms may advertise in order to coordinate consumer expectations on their own brand 
only if they produce goods of similar quality. The firm with the lower quality product has a greater incentive to advertise and the lower quality product will often be more popular.

\section{FRAMEWORK}

We would like to focus on coordinating advertising in markets with consumption externalities. Hence we construct a model which abstracts from all previously analyzed roles of advertising. To abstract from the "persuasive role" of advertising ${ }^{1}$, we assume that consumers are rational and that their preferences are constant in the face of advertising. To abstract from the "informative role" of advertising, either directly or indirectly through signaling, we assume common knowledge of the existence, prices and characteristics of the products. ${ }^{2}$

Consider a market with two brands and a unit continuum of consumers who differ in their taste $(\alpha)$ for the product $\alpha \sim \mathrm{U}[0, \bar{\alpha}]$. Consumers' preferences exhibit positive consumption externalities. The utility the consumer gets from the product is a function of the quality of the product $(\mathrm{V})$ and it is increasing in the number of the people (q) who purchase the same brand. Consumers want at most one product from each brand. Thus, if this is the market for books, some (1993).

${ }^{1}$ See Galbraith (1967), Solow (1967), Dixit and Norman (1978), and Becker and Murphy

${ }^{2}$ See Nelson (1974), Butters (1977), Grossman and Shapiro (1984), Kihlstrom and Riordan (1984), Milgrom and Roberts (1986), Stegeman (1991), Meurer and Stahl (1994), Robert and Stahl (1993), Stahl (1994) and Bagwell and Ramey (1994) for informative advertising. 
consumers may prefer to buy more than one book, but no one will purchase the same book twice. The utility function exhibits diminishing marginal utility. Consumer i's indirect utility is given by:

$$
U_{j}= \begin{cases}0 & \text { if he makes no purchases } \\ \left(\alpha V_{j}+\beta q_{j}-P\right) & \text { if he buys only product } \mathrm{j} \\ \left(\alpha V_{j}+\beta q_{j}-P_{j}\right)+\left(\omega \alpha V_{k}+\beta q_{k}-P_{k}\right) & \text { if he buys product } \mathrm{j} \text { and then } \mathrm{k}\end{cases}
$$

for $j, k \in\{A, B\}$ and $j \neq k, \beta>0, \omega \in(0,1)$. $P$ is the price, $\beta$ is the consumption externality parameter and $\omega$ yields diminishing marginal utility.

For instance, this specification of consumers seems to be a reasonable approximation in the market for movies since people like to chat about movies. If a product with positive consumption externalities has high early sales, later consumers have more incentive to purchase that good and this snowball effect results in high total sales. This feature of markets with consumption externalities is consistent with the belief in the movie industry that a firm's ability to coordinate consumer expectations on its product during the opening weekend will be crucial to its success. ${ }^{3}$ In this paper we model purely coordinating advertising with no word-of-mouth communication about the popularity of the product: Our consumers make their purchasing decisions after firms advertise but before observing the actions of other consumers. Thus in the movie industry interpretation, it is advertising aimed at creating high first-weekend sales that is examined.

Two firms (A, B) have the same constant marginal cost, normalized to zero. The products are of potentially different qualities, $\mathrm{V}_{\mathrm{A}}$ and $\mathrm{V}_{\mathrm{B}}$. Without loss of generality we assume throughout

${ }^{3}$ For example, see "The Won and Lost Weekend," The Economist, November 29, 1997, pg. 87. Studios spend up to three quarters of a movie's promotion budget in the 4-5 days before it opens. 
that $V_{A} \geq V_{B}$. Both $A$ and $B$ 's products sell at price $P$. The producer firm captures a percentage $\gamma \in(0,1]$ of the sales receipts from its product. ${ }^{4}$

In the movie industry interpretation, at the retail level, a movie theater typically carries the products of more than one studio and sells tickets at the same price. That is, at a particular theater the tickets to a popular movie typically sell for the same price as the tickets to an unpopular one. We do not attempt to explain this phenomenon but take it as given. We will focus on the role of advertising abstracting from the interactions between advertising and retail price competition. ${ }^{5}$

In order to guarantee interior solutions to the consumers' problem we make two assumptions on parameter values. ${ }^{6}$ For some of the consumers the product is desirable enough to purchase both goods, even in the absence of consumption externalities: $\bar{\alpha}>\frac{\mathrm{P}}{\omega \mathrm{V}_{\mathrm{B}}}$. And the consumption externality is relatively mild so that a consumer who does not care for the product $(\alpha=0)$ never purchases it just for the externality, even if everybody else is buying it, $\beta<P$. Together these two restrictions on parameter values yield a market which is fundamentally driven by product value. Consumption externalities are important in this market, but not to the extent that they eclipse the fundamental value of the product to consumers.

Before analyzing the case with vertically differentiated products (Section IV), we first examine a market with products of equal quality, $V_{A}=V_{B} \equiv V$. The insights gained about advertising

${ }^{4}$ The typical contract between the movie studios and the theaters ties the producer's revenue directly to ticket sales. This risk-sharing arrangement helps to ensure that the studios have incentives to promote their movies.

${ }^{5}$ Pastine and Pastine (2002) have a dynamic model with homogeneous consumers where firms' advertising and price decisions are endogenously determined. Nevertheless, avoiding these interaction effects permits a much clearer understanding of coordinating advertising in markets with consumption externalities where goods are vertically differentiated.

${ }^{6}$ The analysis of the possible corner solutions in the absence of these assumptions is simple but creates numerous sub-cases without adding any intuition or altering the basic conclusions. 
competition in the homogenous goods case will then be extended to the vertically differentiated goods market.

\section{EQUAL QUALITIES}

Due to consumption externalities, there are multiple equilibria when $V_{A}=V_{B}$ : Consumers can coordinate on one of the products, or there might be no coordination.

\subsection{Multiplicity of Equilibria}

No coordination. A and B are of the same quality and they have the same price. If firms do not engage in some activity to differentiate their products from each other, consumers may have no device to coordinate their expectations about the popularity of the products. Hence in equilibrium, consumers may expect that $A$ and $B$ will sell the same quantity $E\left(q_{A}\right)=E\left(q_{B}\right)=q$.

Since consumers differ in their taste for the product, while some may choose not to purchase either of the items, others may purchase one item and the consumers who have a high taste for the product may purchase both items. A consumer purchases a second item only if the additional benefit from the second product is higher than the price, $\alpha \omega \mathrm{V}+\beta \mathrm{q} \geq \mathrm{P}$. Hence people with

high enough taste $\alpha \geq \frac{\mathrm{P}-\beta \mathrm{q}}{\omega \mathrm{V}}$ will buy A and B. Since $\alpha \sim U[0, \bar{\alpha}]$, the proportion of people who buy both of the products is given by $1-\frac{P-\beta q}{\bar{\alpha} \omega \mathrm{V}}$.

A consumer will not buy either of the products if his marginal benefit from the first purchase is less than the price, $\alpha \mathrm{V}+\beta \mathrm{q} \leq \mathrm{P}$. So consumers with a low taste for the good $\alpha<\frac{\mathrm{P}-\beta \mathrm{q}}{\mathrm{V}}$, will not buy either of the products. Hence, the proportion of people that purchase a single product is $\frac{P-\beta q}{\bar{\alpha} \omega \mathrm{V}}-\frac{P-\beta q}{\bar{\alpha} \mathrm{V}}$. 
People who decide to buy only one item are indifferent between A and B, so they split between the products. Hence the proportion of people that buy a particular product is given by the proportion of consumers that purchase both items plus half of the proportion of consumers that purchase one item. This yields the equilibrium number of people who purchase each good:

$$
q=1-\frac{(P-\beta q)(1+\omega)}{2 \bar{\alpha} \omega V}
$$

Solving for $\mathrm{q}$,

$$
\mathrm{q}=\frac{2 \bar{\alpha} \omega \mathrm{V}-\mathrm{P}(1+\omega)}{2 \bar{\alpha} \omega \mathrm{V}-\beta(1+\omega)} \equiv \tilde{\mathrm{q}}
$$

$\tilde{\mathrm{q}}<1$, since $\mathrm{P}>\beta$. And $\tilde{\mathrm{q}}>0$ since $\bar{\alpha}>\frac{\mathrm{P}}{\omega \mathrm{V}}$. As the price goes up, quantity demanded goes down. An increase in the consumption externality parameter $\beta$ leads to an increase in the quantity demanded.

Coordinated Demand Equilibria. Suppose that consumers believe that firm $j$ will sell more than firm $k, E\left(q_{j}\right)>E\left(q_{k}\right) \forall j, k \in\{A, B\}$ where $\mathrm{j} \neq k$. Since all else is equal, consumers would prefer $\mathrm{j}$ 's product due to the consumption externalities. Consumers who purchase k, are the ones who purchase both $\mathrm{j}$ and $\mathrm{k}$. A consumer purchases the second item $\mathrm{k}$ if the additional benefit from $\mathrm{k}$ is higher than the price, $\alpha \omega \mathrm{V}+\beta \mathrm{q}_{\mathrm{k}} \geq \mathrm{P}$. The proportion of people who buy $\mathrm{k}$ is then given by:

$$
q_{k}=\left(1-\frac{P-\beta q_{k}}{\bar{\alpha} \omega V}\right)
$$

Solving for $\mathrm{q}_{\mathrm{k}}$ yields:

$$
\mathrm{q}_{\mathrm{k}}=\frac{\bar{\alpha} \omega \mathrm{V}-\mathrm{P}}{\bar{\alpha} \omega \mathrm{V}-\beta} \equiv \underline{\mathrm{q}}
$$

Consumers whose marginal benefit from the first purchase is higher than price buy $j, \alpha V+\beta q_{j} \geq P$. So people with $\alpha \geq \frac{P-\beta q_{j}}{V}$ purchase $j$. The proportion of the people who purchase $j$ is:

$$
q_{j}=1-\frac{P-\beta q_{j}}{\bar{\alpha} V}
$$


Solving for $\mathrm{q}_{\mathrm{j}}$ yields:

$$
\mathrm{q}_{\mathrm{j}}=\frac{\bar{\alpha} \mathrm{V}-\mathrm{P}}{\bar{\alpha} \mathrm{V}-\beta} \equiv \overline{\mathrm{q}}
$$

Inspection of (5) and (7) reveals that $\overline{\mathrm{q}}>\underline{\mathrm{q}}$ since $\mathrm{P}>\beta$ and $\omega<1$. The product that faces the coordinated demand sells more due to consumption externalities. The proportion of people that buy $\mathrm{j}$ in the coordinated demand equilibrium is greater than the proportion of people that buy $\mathrm{j}$ when there is no coordination, $\overline{\mathrm{q}}>\tilde{\mathrm{q}}$. The proportion of people that buy $\mathrm{k}$ declines when consumers coordinate on $\mathrm{j}$ compared to the case where there is no coordination, $\underline{\mathrm{q}}<\tilde{\mathrm{q}}$.

\subsection{The Role of Advertising}

There is an equilibrium where consumers coordinate on $\mathrm{A}$ and there is also an equilibrium where consumers coordinate on B. Firms have preferences over these possible equilibria. Thus, firms may try to differentiate themselves via advertising to coordinate consumer expectations on their own brand.

In light of the multiplicity of equilibria, imagine a consumer who observes an advertising campaign. The consumer could suppose either that the advertising was a mistake, or that advertising will lead to increased sales. And in fact there are several equilibria so either set of expectations is rational. But they are not equally plausible as general predictions of consumer behavior. If a firm invests in advertising it must believe that advertising increases sales, and consumers are likely to take this into account when forming their own expectations. For consumers 
to ignore advertising in forming their expectations they must treat all observed advertising as costly mistakes by firms. ${ }^{7}$

\subsection{The Nature of Advertising Competition}

Let us momentarily postulate that the firm that advertises more heavily can coordinate consumers on its own brand, and find the equilibrium in the advertising competition. Using this we will then argue that this is likely to be the equilibrium outcome: It is indeed rational for the consumer to prefer to purchase the more heavily advertised product.

Abstracting from all other functions of advertising, when the only role of advertising is to coordinate consumer expectations, advertising competition has the same form as the first-price allpay auction. ${ }^{8}$ In a first-price all-pay auction all participants must pay their bids regardless of whether they win the auction or not, and the highest bidder receives the prize. In our framework, the more heavily advertised brand (the firm with the highest bid in the form of advertising expense) can capture the popular brand position. The value of winning the auction for a firm is the difference in the profits the firm would get if consumers coordinate on its product versus if consumers coordinate on the rival's product. If a firm out advertises its rival, its sales are given by (7) and if its competitor out advertises it, its sales are given by (5). Therefore the value of "winning" the

${ }^{7}$ Firms in markets with significant consumption externalities often try to encourage this type of reasoning. In the early months of 1995, during the height of its advertising campaign for $\mathrm{OS} / 2$, IBM frequently cited its $\$ 500$ million investment in the operating system. When Windows 95 was launched in August 1995, Microsoft widely publicized that it was spending \$200 million on advertising alone. See, for example, Panettieri (1995) and Rebello and Kuntz (1995).

${ }^{8}$ The all-pay auction form has been analyzed by Tullock (1980), Hillman and Riley (1989) and Baye et al. (1993,1996). The proofs used here are adapted from Ellingsen (1991). General statements on expected payoffs can be found in Baye, Kovenock and De Vries (1993). All-pay auctions have been widely used to model lobbying for monopoly rents, R\&D races, political campaigns, tournaments and job promotion. 
advertising competition $(\Gamma)$ to each firm over and above the value of losing is given by the difference between these quantities, $\overline{\mathrm{q}}$ and $\underline{\mathrm{q}}$, times the price of the product, times the share of sales which goes to the producer:

$$
\Gamma_{\mathrm{A}}=\Gamma_{\mathrm{B}}=\frac{\gamma \mathrm{P}(\mathrm{P}-\beta) \bar{\alpha} \mathrm{V}(1-\omega)}{(\bar{\alpha} \mathrm{V}-\beta)(\bar{\alpha} \omega \mathrm{V}-\beta)}
$$

Since the firms' problems are symmetric, the value of winning the advertising competition is the same for both producers.

In this section we will derive the properties of the equilibrium. Lemmas 1-4 below will also be employed when we discuss the case of vertically differentiated products. While $\Gamma_{A}=\Gamma_{B}$ when goods are homogenous, this will not be the case when goods are of different qualities. In the next section we will show that the value of winning the advertising competition is higher for the low quality product firm; $\Gamma_{A}<\Gamma_{B}$. To avoid repetition, Lemmas 1-4 are established for $\Gamma_{A} \leq \Gamma_{B}$ even though in the homogenous product case we only need the arguments for $\Gamma_{A}=\Gamma_{B}$.

Lemma 1: Neither firm will put a probability mass point on any advertising level greater than zero when $\Gamma_{A} \leq \Gamma_{B}$.

Proof: Define a range $\mathrm{A}_{\mathrm{i}}$ as $(0, \mathrm{x})$ where $\mathrm{x}$ is an arbitrary number greater than $\Gamma_{B}$. Suppose the lowest mass point of firm $\mathrm{i}$ in $\mathrm{A}_{\mathrm{i}}$ is given by $a^{*} \in A$. Then firm $\mathrm{j}$ would not put any probability at $a_{j}=a_{i}^{*}$ as a slight increase in his advertising would result in a discrete increase in the probability of winning. As there is no probability of $a_{j}=a_{i}^{*}$, firm i could lower his advertising slightly without changing his probability of winning. 
Lemma 2: Both firms have infimum advertising levels of zero. The expected value of the game to firm $A$ is zero when $\Gamma_{A} \leq \Gamma_{B}$.

Proof: Firm A will never advertise more than $\Gamma_{A}$. By Lemma 1, there is zero probability of A advertising exactly $\Gamma_{A}$ so firm B will never advertise greater than $\Gamma_{A}$. Since there can be no probability mass at $\Gamma_{A}$ by Lemma 1, each firms' infimum advertising level must be less than $\Gamma_{A}$. Suppose that firm $i$ has an infimum advertising level of $a_{i}^{\text {inf }} \in\left(0, \Gamma_{A}\right)$. Then firm $\mathrm{j}$ would never choose $0<a_{j} \leq a_{i}^{\text {inf }}$. If he did he would be paying a positive amount and would lose for sure, since by Lemma 1 , the probability of firm i choosing exactly $a_{i}^{\text {inf }}$ is zero in this range. Therefore firm $\mathrm{i}$ could lower its infimum advertising level without changing the probability of winning.

If firm A had an expected value from the game greater than zero, it would have to have a non-zero probability of winning at its infimum advertising level since all advertising levels in the support of the mixed strategy must yield the same expected payoff. From Lemma 1 this would imply that firm B would be putting a probability mass at zero advertising. If so firm A would never advertise zero since it could gain a discrete increase its probability of winning at negligible cost by advertising just slightly more than zero. Thus firm B would lose with certainty with zero advertising, yielding a payoff of zero. In this candidate equilibrium firm B would be earning zero expected profits and A would be earning positive expected profits so its suprimum advertising level would have to be strictly below $\Gamma_{\mathrm{A}}$. In that case firm B could raise its advertising to just above A's suprimum level and make positive expected profits. Hence in equilibrium the expected value of the game to firm A must be zero. 
Lemma 3: When $\Gamma_{A} \leq \Gamma_{B}$, both firms have a suprimum advertising level of $\Gamma_{A}$. The expected value of the game to firm $B$ is $\Gamma_{B}-\Gamma_{A}$. Hence when $\Gamma_{A}=\Gamma_{B}$ the expected value of the game to firm $B$ is zero.

Proof: If firm B had a suprimum level of advertising of $a_{B}^{\prime m}<\Gamma_{A}$, firm A could win for sure with that level of advertising since by Lemma 1 the probability of firm B choosing exactly $a_{B}^{\text {sq }}$ is zero. However this would result in a positive payoff for A, a contradiction of Lemma 2.

Suppose that firm A had a suprimum advertising level of $a_{A}^{\text {sp }}<\Gamma_{A}$. Then firm B would never set $a_{B}>a_{A}^{\text {sup }}$ as he can win for sure with that level of advertising since by Lemma 1 the probability of firm A choosing exactly $a_{A}^{\mathbf{S P}}$ is zero. A contradiction of the first part of the proof of this lemma.

Firm B wins for sure with his suprimum advertising level since by Lemma 1 the probability of firm A choosing exactly that level is zero. Since $\Gamma_{\mathrm{A}}$ is in the support of his mixed strategy and he wins for sure with that advertising level, the expected payoff for firm $\mathrm{B}$ is $\Gamma_{B}-\Gamma_{A}$.

Lemma 4: Each firm must have positive probability almost everywhere on $a_{i} \in\left(0, \Gamma_{A}\right]$ when $\Gamma_{A} \leq \Gamma_{B}$.

Proof: Suppose there were an interval $(t, s)$ in where firm $i$ had zero probability of advertising. Then firm $\mathrm{j}$ would have zero probability of advertising in that interval since it could lower its advertising to $t$ and have the same chance of winning. But in this case firm i would never bid $s+\varepsilon$ as he could lower his advertising to $t$, saving $s+\varepsilon-t$ in advertising costs and losing only the probability that $\mathrm{j}$ advertises in the range $[s, s+\varepsilon]$. By Lemma 1 the loss in probability is negligible for small $\varepsilon$. 
Proposition 1: When goods are of equal qualities, no pure-strategy equilibrium exists. The mixedstrategy equilibrium involves almost everywhere continuous mixed strategies where both firms mix in the range $\left[0, \Gamma_{\mathrm{A}}\right]$. The advertising competition results in the expected dissipation of all gains to advertising.

Proof: From Lemma 1 there can be no pure-strategy equilibrium with advertising levels greater than zero. If firm A is playing a pure strategy of zero advertising then firm B would play a pure strategy of advertising just above zero, winning for sure with negligible advertising expenses. This would contradict Lemma 1, hence there can be no pure-strategy equilibrium. Both firms have continuous mixed strategies almost everywhere on $\left[0, \Gamma_{\mathrm{A}}\right]$ by Lemma 4 . Expected values of the advertising competition for each firm are zero by Lemmas 2 and $3^{9}$.

Ex-ante each firm is indifferent between advertising and simply allowing the other to capture the coordinated demand. While the actualized profit of the firm depends on the outcome of the mixed-strategy equilibrium, the expected profit is simply equal to the profit that the firm would get if it passively allowed its rival to coordinate consumer expectations on its product. In this case, the firm's sales would be given by q which is strictly less than the sales the firm would get if neither firm advertised, $\tilde{\mathrm{q}}$. Thus both firms would be better off if they could agree not to advertise. However, each would have an incentive to cheat on such an agreement. If the rival were not to advertise then the firm could coordinate consumer expectations on its product with a minimal advertising expense and capture sales of $\bar{q}$ which are strictly higher than the sales it could get if it abided by the agreement.

Due to advertising more people buy at least one product (a business creation effect). When consumers coordinate their expectations on a brand, positive consumption externality creates an additional incentive for the consumers to buy that brand. In the movie industry interpretation this

${ }^{9}$ See Hillman and Riley (1989) or Ellingsen (1991) for the full derivation of equilibrium strategies. The literature on all-pay auctions is extensive. With more than two players there may not be a unique equilibrium, but the result on the costs for the two players with the highest valuation can be obtained across all equilibria, see Baye, Kovenock and De Vries (1993). 
means that even people who do not enjoy movies very much go to the movies, since they expect to socialize with more people. Without coordination, only people with $\alpha \geq \frac{\mathrm{P}-\beta \tilde{\mathrm{q}}}{\mathrm{V}_{\mathrm{m}}}$ purchase the good. With coordination all the people with $\alpha \geq \frac{\mathrm{P}-\beta \overline{\mathrm{q}}}{\mathrm{V}}$ go to the movies, where $\frac{\mathrm{P}-\beta \overline{\mathrm{q}}}{\mathrm{V}}<\frac{\mathrm{P}-\beta \tilde{\mathrm{q}}}{\mathrm{V}}$ since $\overline{\mathrm{q}}>\tilde{\mathrm{q}}$.

Due to advertising, fewer people buy the less advertised product (a business stealing effect). Without advertising consumers who were going to purchase one item would split between the products. With advertising the firm with lower advertising no longer gets these customers. It only captures consumers who value the good enough to purchase both. Hence, the incentive to purchase the second item declines. From (3) and (5), $\underline{\mathrm{q}}<\tilde{\mathrm{q}}$.

Also notice that total quantity sold goes down (a business dissipation effect). Total sales when there is no advertising is the summation of the demand for A and demand for B, given by $2 \tilde{\mathbf{q}}$. When one firm advertises more than the other, one gets $\overline{\mathrm{q}}$ and the other gets $\underline{\mathrm{q}}$. There is a reduction in the total sales,

$$
\underline{\mathrm{q}}+\overline{\mathrm{q}}-2 \tilde{\mathrm{q}}=-\frac{(\mathrm{P}-\beta)(1-\omega)^{2} \beta \bar{\alpha} \mathrm{V}}{(\bar{\alpha} \mathrm{V}-\beta)(\bar{\alpha} \omega \mathrm{V}-\beta)(2 \bar{\alpha} \omega \mathrm{V}-\beta(1+\omega))}<0
$$

With coordination, one firm has high demand and the other has low demand. Hence the incentive for a consumer to buy his first product increases, and the incentive to buy his second decreases. But since the consumer has diminishing marginal utility from the consumption of the product, the intrinsic value of the second purchase is less important relative to the consumption externality than it is for the first purchase. Hence coordination increases the sales of highly advertised product less than it decreases the sales for the less advertised product.

As a result of the stochastic nature of the advertising competition, ex-post the firm which is out advertised will have regrets. But the consumer will realize that firms advertise because they expect advertising to increase their sales. So the individual consumer will realize that firms believe that advertising is being used as a coordination device, and that firms are confident enough about this belief to invest large sums of money. Hence it will in fact be in the best interest of a consumer to buy the more heavily advertised brand. In aggregate, this leads to higher sales, higher 
consumption externalities and hence greater consumer surplus from the more heavily advertised product.

\section{VERTICAL DIFFERENTIATION}

In markets with vertical differentiation consumers can learn about the qualities of the products based on trusted critics. Computer magazines rate the qualities of software packages. There are consumer reports on the reliability of different brand name automobiles. In the movie industry, Reinstein and Snyder (2005) find that reviews have a large and significant effect on consumers' expectation of film quality. We assume that qualities of the products are common knowledge and $\mathrm{V}_{\mathrm{A}}>\mathrm{V}_{\mathrm{B}}$. We first examine whether multiple equilibria exist when one product is of superior quality. We then discuss the role of advertising as a coordination device in markets with vertically differentiated products.

Coordinate on A. Suppose that consumers believe that more people will purchase A. Then the consumer prefers A for two reasons. First, he expects to enjoy A more due to its higher quality. Secondly, he expects to derive higher consumption externalities from A. The only consumers that end up buying $\mathrm{B}$ are the ones who purchase both of the products. The second item ${ }^{10}$ yields additional surplus equal to $\left(\alpha \omega V_{B}+\beta q_{B}-P\right)$. Therefore, consumers with $\alpha \geq \frac{P-\beta q_{B}}{\omega V_{B}}$ buy B. Since $\alpha \sim \mathrm{U}[0, \bar{\alpha}]$, solving for the equilibrium $\mathrm{q}_{\mathrm{B}}$,

Since $\mathrm{P}>\beta, 0<\mathrm{q}_{\mathrm{B}}<1$.

$$
\mathrm{q}_{\mathrm{B}}=\frac{\bar{\alpha} \omega \mathrm{V}_{\mathrm{B}}-\mathrm{P}}{\bar{\alpha} \omega \mathrm{V}_{\mathrm{B}}-\beta}
$$

Everyone with a positive consumer surplus from $A$, with $\alpha$ such that $\alpha V_{A}+\beta q_{A} \geq P$, buys $A$. Solving for the equilibrium $\mathrm{q}_{\mathrm{A}}$,

since $V_{A}>V_{B}$, sales of $A$ are greater than the sales of $B, q_{A}>q_{B}$.

$$
\mathrm{q}_{\mathrm{A}}=\frac{\bar{\alpha} \mathrm{V}_{\mathrm{A}}-\mathrm{P}}{\bar{\alpha} \mathrm{V}_{\mathrm{A}}-\beta}
$$

${ }^{10} \mathrm{An}$ individual who is purchasing both goods will always purchase A first since $\mathrm{V}_{\mathrm{A}}+\omega \mathrm{V}_{\mathrm{B}}>\mathrm{V}_{\mathrm{B}}+\omega \mathrm{V}_{\mathrm{A}}$. 
Coordinate on B. Can it be rational for consumers to believe that the lower quality product B will be more popular? Below we will show that $E\left(q_{A}\right)<E\left(q_{B}\right)$ is only rational when $A$ and $B$ are of similar qualities. If the quality difference between the two products is too large, then the expectation that $\mathrm{q}_{\mathrm{B}}>\mathrm{q}_{\mathrm{A}}$ is not rational, and hence there is no multiplicity of equilibria. Only when products are of similar qualities may advertising have a coordinating role to play in this market.

If consumer $\mathrm{i}$ believes that the lower quality product will sell more, then the product that the consumer prefers to buy depends on the consumer's taste for the intrinsic value of the good. For high $\alpha_{i}$ such that $\alpha_{i} V_{A}+\beta q_{A}>\alpha_{i} V_{B}+\beta q_{B}$, consumer i would prefer the high-quality product $A$. Define $\tilde{\alpha}$ as the critical level where a consumer is indifferent between $A$ and $B$ if he is buying his first item:

$$
\tilde{\alpha}=\frac{\beta\left(\mathrm{q}_{\mathrm{B}}-\mathrm{q}_{\mathrm{A}}\right)}{\mathrm{V}_{\mathrm{A}}-\mathrm{V}_{\mathrm{B}}}
$$

Consumers with $\alpha \geq \tilde{\alpha}$ prefer A over $\mathrm{B}$, due to its high quality, and consumers with $\alpha<\tilde{\alpha}$ prefer $\mathrm{B}$ over A, due to the consumption externality.

Define $\alpha^{\prime}$ such that if $\alpha_{\mathrm{i}}$ is low $\left(\alpha_{\mathrm{i}}<\alpha^{\prime}\right)$, consumer i will not buy either of the products. Define $\alpha^{\prime \prime}$ such that if $\alpha_{\mathrm{i}}$ is high $\left(\alpha_{\mathrm{i}}>\alpha^{\prime \prime}\right)$, he buys both of the products. The critical values $\alpha^{\prime}$ and $\alpha^{\prime \prime}$ will be derived shortly. If $\alpha_{\mathrm{i}}$ takes an intermediate value, $\alpha^{\prime}<\alpha \leq \alpha^{\prime \prime}$, he will buy one, and the one he chooses will depend on the relationship between $\alpha_{i}$ and $\tilde{\alpha}$. There are three potential cases $\tilde{\alpha} \leq \alpha^{\prime}$, $\alpha^{\prime}<\tilde{\alpha} \leq \alpha^{\prime \prime}$, and $\tilde{\alpha}>\alpha^{\prime \prime}$. We will show that the only possibility for rational expectations of $\mathrm{q}_{\mathrm{B}}>\mathrm{q}_{\mathrm{A}}$ is in the third case where the parameter values are such that $\tilde{\alpha}>\alpha$.

The first case $\left(\tilde{\alpha} \leq \alpha^{\prime}\right)$ directly implies that $\mathrm{q}_{\mathrm{B}}<\mathrm{q}_{\mathrm{A}}$ and so the consumers' expectations that $\mathrm{q}_{\mathrm{B}}>\mathrm{q}_{\mathrm{A}}$ are not rational. The second case $\left(\alpha^{\prime}<\tilde{\alpha} \leq \alpha^{\prime \prime}\right)$ is less obvious, but is also not possible in equilibrium. To see this notice that in this case everyone with $\alpha_{i} \geq \tilde{\alpha}$ will buy $A$ so, $q_{A}=1-\frac{\beta\left(q_{B}-q_{A}\right)}{\bar{\alpha}\left(V_{A}-V_{B}\right)}$. Solving for the quantity firm A sells, $q_{A}=\frac{\bar{\alpha}\left(V_{A}-V_{B}\right)-\beta q_{B}}{\bar{\alpha}\left(V_{A}-V_{B}\right)-\beta}$. This yields $\mathrm{q}_{\mathrm{A}} \geq 1$, so if the parameters are such that $\tilde{\alpha} \leq \alpha$ "consumer expectations of $\mathrm{q}_{\mathrm{B}}>\mathrm{q}_{\mathrm{A}}$ are not rational.

Thus the only possibility for rational expectations of $\mathrm{q}_{B}>\mathrm{q}_{A}$ is if $\tilde{\alpha}>\alpha^{\prime \prime}$. As before, $\alpha^{\prime \prime}$ is where the consumer's additional benefit from buying two items instead of one is just equal to the price of the product. If the consumer buys only one item he will buy B. The net benefit from purchasing one item is therefore $\alpha_{i} V_{B}+\beta q_{B}-P$. The net benefit from two items is equal to $\left[\alpha_{i} V_{A}+\beta q_{A}-P+\alpha_{i} \omega V_{B}+\beta q_{B}-P\right]$. Hence the additional net benefit from buying the second item 
is equal to $\left[\alpha_{\mathrm{i}} \mathrm{V}_{\mathrm{A}}-\alpha_{\mathrm{i}}(1-\omega) \mathrm{V}_{\mathrm{B}}+\beta \mathrm{q}_{\mathrm{A}}-\mathrm{P}\right]$. The additional net benefit from purchasing the second item is zero for the consumer with $\alpha_{i}=\alpha$ ",

$$
\alpha^{\prime \prime}=\frac{\mathrm{P}-\beta \mathrm{q}_{\mathrm{A}}}{\mathrm{V}_{\mathrm{A}}-(1-\omega) \mathrm{V}_{\mathrm{B}}}
$$

The only consumers who buy $\mathrm{A}$ are those who value the good so much that they buy both $\mathrm{A}$ and $B\left(\alpha_{i}>\alpha^{\prime \prime}\right)$. Therefore $q_{A}$ is given by,

solving for $\mathrm{q}_{\mathrm{A}}$,

$$
\mathrm{q}_{\mathrm{A}}=1-\frac{\mathrm{P}-\beta \mathrm{q}_{\mathrm{A}}}{\bar{\alpha} \mathrm{V}_{\mathrm{A}}-\bar{\alpha}(1-\omega) \mathrm{V}_{\mathrm{B}}}
$$

$\mathrm{q}_{\mathrm{A}} \in(0,1)$ since $\mathrm{P}>\beta$ and $\bar{\alpha} \omega \mathrm{V}_{\mathrm{A}}>\mathrm{P}$.

$$
\mathrm{q}_{\mathrm{A}}=\frac{\left[\bar{\alpha} \mathrm{V}_{\mathrm{A}}-\bar{\alpha}(1-\omega) \mathrm{V}_{\mathrm{B}}\right]-\mathrm{P}}{\left[\bar{\alpha} \mathrm{V}_{\mathrm{A}}-\bar{\alpha}(1-\omega) \mathrm{V}_{\mathrm{B}}\right]-\beta}
$$

Consumers whose net benefit from purchasing $B$ is positive, $\alpha V_{B}+\beta q_{B}-P>0$ buy $B$. This yields the critical value $\alpha$,

$$
\alpha^{\prime}=\frac{P-\beta q_{B}}{V_{B}}
$$

All consumers with $\alpha_{i}>\alpha^{\prime}$ purchase $B$, therefore $q_{B}$ is given by,

solving for $\mathrm{q}_{\mathrm{B}}$,

$$
\mathrm{q}_{\mathrm{B}}=1-\frac{\mathrm{P}-\beta \mathrm{q}_{\mathrm{B}}}{\bar{\alpha} \mathrm{V}_{\mathrm{B}}}
$$

$\mathrm{q}_{\mathrm{B}} \in(0,1)$ since $\mathrm{P}>\beta$, and $\bar{\alpha} \omega \mathrm{V}_{\mathrm{B}}>\mathrm{P}$. Thus,

$$
\mathrm{q}_{\mathrm{B}}=\frac{\bar{\alpha} \mathrm{V}_{\mathrm{B}}-\mathrm{P}}{\bar{\alpha} \mathrm{V}_{\mathrm{B}}-\beta}
$$

$$
\mathrm{q}_{\mathrm{B}}-\mathrm{q}_{\mathrm{A}}=\frac{\bar{\alpha}(\mathrm{P}-\beta)\left[(1-\omega) \mathrm{V}_{\mathrm{B}}-\left(\mathrm{V}_{\mathrm{A}}-\mathrm{V}_{\mathrm{B}}\right)\right]}{\left(\bar{\alpha} \mathrm{V}_{\mathrm{B}}-\beta\right)\left[\bar{\alpha}\left(\mathrm{V}_{\mathrm{A}}-\mathrm{V}_{\mathrm{B}}\right)+\bar{\alpha} \omega \mathrm{V}_{\mathrm{B}}-\beta\right]}
$$

$\mathrm{q}_{\mathrm{B}}>\mathrm{q}_{\mathrm{A}}$ if $(1-\omega) \mathrm{V}_{\mathrm{B}}>\left(\mathrm{V}_{\mathrm{A}}-\mathrm{V}_{\mathrm{B}}\right)$.

These results also require that $\alpha^{\prime \prime}<\tilde{\alpha}$ which imposes the condition,

$$
\frac{\mathrm{P}-\beta \mathrm{q}_{\mathrm{A}}}{\mathrm{V}_{\mathrm{A}}-(1-\omega) \mathrm{V}_{\mathrm{B}}}<\frac{\beta\left(\mathrm{q}_{\mathrm{B}}-\mathrm{q}_{\mathrm{A}}\right)}{\left(\mathrm{V}_{\mathrm{A}}-\mathrm{V}_{\mathrm{B}}\right)}
$$

Substituting in $\mathrm{q}_{\mathrm{A}}$ from (15) and $\left(\mathrm{q}_{\mathrm{B}}-\mathrm{q}_{\mathrm{A}}\right)$ from (19) and rearranging (20) yields,

$$
\left(\mathrm{V}_{\mathrm{A}}-\mathrm{V}_{\mathrm{B}}\right)<\frac{(1-\omega) \beta}{\bar{\alpha}}
$$

(21) is the necessary and sufficient condition for the existence of an equilibrium where consumers coordinate on the low-quality good. If the quality difference between the two products is too large, then the expectation that $\mathrm{q}_{\mathrm{B}}>\mathrm{q}_{\mathrm{A}}$ is not rational, and advertising will not have a coordinating role to play in this market. 
Proposition 2: If the quality difference between the products is too large we will not observe advertising for coordination purposes.

Proof: If the qualities of the two goods are very different - loosely speaking, one movie receives two thumbs up, the other two thumbs down, formally $\left[\mathrm{V}_{\mathrm{A}}-\mathrm{V}_{\mathrm{B}} \geq \frac{(1-\omega) \beta}{\bar{\alpha}}\right]-$ there is only one equilibrium and it involves consumers coordinating on the high-quality good. In this case, everyone who buys a product purchases the higher quality one, and only those people who really like the product will purchase the lower quality one as well. Suppose B is a very low-quality brand but that firm B did advertise. Because B is so poor, there is no rational expectations equilibrium where consumers coordinate on B. In this situation, purchasing the higher quality product is the only reasonable behavior, and consumers will coordinate on the higher quality product, even if faced with advertising for the low-quality product. Hence rational firms will choose not to advertise when the quality difference between the products is too large.

When there are significant quality differences, there is no multiplicity of equilibria and firms cannot coordinate consumer expectations using advertising. Hence the quality assessments, such as movie reviews, are serving an informative role, but also, implicitly, they are serving a coordinating function.

From (21), notice that advertising may serve a coordinating role when the consumption externality $(\beta)$ is large. If the consumption externality is small, the quality of the products becomes relatively more important in the purchasing decisions of the consumers, and the coordinating function is served by quality differences. If the importance of quality versus externality is high, advertising will not coordinate consumer expectations.

When the quality difference between the products is not too drastic, that is for parameter values where (21) holds, coordination via product quality may be difficult to achieve. Of course, if all else is equal it is quite natural for consumers to coordinate on the high-quality good. However, the producer of the low-quality good has strong incentives to ensure that all else is not equal. The fundamental problem is that there are two equilibria, and each individual consumer must try to predict which equilibrium the other consumers are going to play. 
There is a subgame-perfect Nash equilibrium where consumers coordinate on the highquality product and ignore all advertising. In this equilibrium firms would not advertise. Notice that for this equilibrium to survive, the off-equilibrium beliefs must be such that consumer interpret any positive level of advertising as irrational behavior of the firm. Now suppose that the producer of the lower quality product does actually mount a costly advertising campaign. An individual consumer could suppose that the firm engages in the advertising campaign because it has information that consumers use advertising to coordinate their expectations on one of the equilibria. In this case, a consumer who is going to buy only one product would prefer B, firm B's sales would increase, vindicating its investment in advertising. Therefore, when the quality of the products are not too dissimilar, information on product quality may not be the deciding factor in coordinating consumer expectations. However, it will have a very significant effect on the incentives that the two firms face in their advertising competition.

Proposition 3: The value of winning the advertising competition is higher for the firm with the low-quality product.

Proof: The value of winning the advertising competition for a firm is proportional to the difference in sales when it coordinates consumers on its brand versus when the rival captures the coordinated demand. So for $\mathrm{A}$ the value of winning the advertising competition is proportional to the difference between (11) and (15):

$$
\Gamma_{\mathrm{A}}=\frac{\gamma \mathrm{P} \bar{\alpha}(\mathrm{P}-\beta)(1-\omega) \mathrm{V}_{\mathrm{B}}}{\left(\bar{\alpha} \mathrm{V}_{\mathrm{A}}-\beta\right)\left[\left(\bar{\alpha} \omega \mathrm{V}_{\mathrm{B}}-\beta\right)+\bar{\alpha}\left(\mathrm{V}_{\mathrm{A}}-\mathrm{V}_{\mathrm{B}}\right)\right]}
$$

For $\mathrm{B}$, the value of winning the advertising competition is proportional to the difference between (10) and (18):

$$
\Gamma_{\mathrm{B}}=\frac{\gamma \mathrm{P} \bar{\alpha}(\mathrm{P}-\beta)(1-\omega) \mathrm{V}_{\mathrm{B}}}{\left(\bar{\alpha} \mathrm{V}_{\mathrm{B}}-\beta\right)\left(\bar{\alpha} \omega \mathrm{V}_{\mathrm{B}}-\beta\right)}
$$

The numerators of (22) and (23) are the same but the denominator of (23) is small since $V_{A}>V_{B}$. Hence the value of winning the advertising competition is higher for firm B. 
A is the higher quality product. Even when it does not coordinate consumers on its brand it still sells well due to its high quality. If A coordinates demand, B only gets a low level of sales due to its low quality. Moving from this low demand to the coordinated demand yields a big change in sales for B. Hence the value of winning the advertising competition is higher for the low-quality product firm.

Coordinating advertising competition when firms have vertically differentiated products has the same form as an all-pay auction where bidders have asymmetric valuations.

Proposition 4: When goods are vertically differentiated, no pure-strategy equilibrium exists. The mixed-strategy equilibrium involves almost everywhere continuous mixed strategies where both firms mix in the range $\left[0, \Gamma_{\mathrm{A}}\right]$. The advertising competition results in the expected dissipation of all gains to advertising for the high quality firm and the expected value of the competition is equal to $\Gamma_{B}-\Gamma_{A}>0$ for the low quality firm.

Proof: As in the homogenous products case, from Lemma 1 there can be no pure-strategy equilibrium with advertising levels greater than zero. If firm A is playing a pure strategy of zero advertising then firm B would play a pure strategy of advertising just above zero. And zero advertising would not be best response of A. Hence there can be no pure-strategy equilibrium. Both firms have continuous mixed strategies almost everywhere on $\left[0, \Gamma_{\mathrm{A}}\right]$ by Lemma 4 . The expected value of the advertising competition for firm A is zero by Lemma 2. The expected value of the advertising competition for firm $\mathrm{B}$ is $\Gamma_{\mathrm{B}}-\Gamma_{\mathrm{A}}$ by Lemma 3. This expression is positive by Proposition 3.

Firm A would never bid higher than the value of the auction $\Gamma_{\mathrm{A}}$. Firm B could always win the competition by bidding slightly higher than $\Gamma_{\mathrm{A}}$ and collect the prize. This leaves $\mathrm{B}$ with an advantage in the advertising competition equal to the difference in valuations. In equilibrium it is able to capture an expected profit from the advertising competition equal to $\Gamma_{B}-\Gamma_{A}>0$.

While the firm with the low-quality product strictly prefers to engage in advertising competition, the expected profit created by entering the advertising competition for the firm with the high-quality product is equal to zero. The firm with the high-quality product is indifferent 
between entering the competition or not. However it would not be an equilibrium strategy for A not to enter the competition: Any announcement suggesting that A will not advertise would not be credible. Hence in equilibrium both firms will advertise. The outcome of the advertising competition will be stochastic. Sometimes we will observe the producer of the high-quality product advertising more, and other times we will observe the producer of the low-quality product advertising more.

Proposition 5: The firm with the low-quality product is more likely to win the advertising competition. As long as quality difference is not too drastic consumers will more often coordinate on the low-quality product.

Proof: Define $\mathrm{G}_{\mathrm{A}}(\mathrm{a})$ as the probability of firm A having an advertising level less than or equal to 'a'. And $\mathrm{G}_{\mathrm{B}}(\mathrm{a})$ represents firm B's cumulative probability distribution. The expected value of the advertising competition to firm A is zero by Proposition 4. So when firm A advertises ' $a$ ', the expected value created due to advertising competition for firm A is given by:

$$
0=\mathrm{G}_{\mathrm{B}}(\mathrm{a})\left(\Gamma_{\mathrm{A}}-\mathrm{a}\right)+\left(1-\mathrm{G}_{\mathrm{B}}(\mathrm{a})\right)(-\mathrm{a})
$$

Solving for $\mathrm{G}_{\mathrm{B}}(\mathrm{a})$ yields:

$$
\mathrm{G}_{\mathrm{B}}(\mathrm{a})=\frac{\mathrm{a}}{\Gamma_{\mathrm{A}}}
$$

The expected value of the advertising competition to firm $B$ is given by $\Gamma_{B}-\Gamma_{A}$. When firm $B$ advertises ' $a$ ', the expected value created due to advertising competition for firm B is given by:

$$
\Gamma_{\mathrm{B}}-\Gamma_{\mathrm{A}}=\mathrm{G}_{\mathrm{A}}(\mathrm{a})\left(\Gamma_{\mathrm{B}}-\mathrm{a}\right)+\left(1-\mathrm{G}_{\mathrm{A}}(\mathrm{a})\right)(-\mathrm{a})
$$

Solving for $\mathrm{G}_{\mathrm{A}}(\mathrm{a})$ yields:

$$
\mathrm{G}_{\mathrm{A}}(\mathrm{a})=\frac{\Gamma_{\mathrm{B}}-\Gamma_{\mathrm{A}}+\mathrm{a}}{\Gamma_{\mathrm{B}}}
$$

The probability of firm A winning the advertising competition is given by the probability that $\mathrm{A}$ advertises ' $\mathrm{a}$ ' times the probability that $\mathrm{B}$ advertises less than ' $\mathrm{a}$ ', integrated over the support of the mixed strategy:

$$
\int_{0}^{\Gamma_{\mathrm{A}}} \mathrm{G}_{\mathrm{B}}(\mathrm{x}) \frac{\partial \mathrm{G}_{\mathrm{A}}(\mathrm{x})}{\partial \mathrm{x}} \mathrm{dx}=\frac{\Gamma_{\mathrm{A}}}{2 \Gamma_{\mathrm{B}}}
$$


Similarly, the probability of coordinating on B is given by:

$$
\int_{0}^{\Gamma_{A}} G_{A}(x) \frac{\partial G_{B}(x)}{\partial x} d x=\frac{2 \Gamma_{B}-\Gamma_{A}}{2 \Gamma_{B}}
$$

Since $\Gamma_{\mathrm{B}}>\Gamma_{\mathrm{A}}$, the probability that consumers coordinate on the low-quality product is higher than the probability that consumers coordinate on the high-quality product.

This for instance implies that consumers will watch many mediocre movies just for the consumption externality. Nevertheless, the movies with the highest sales will be the high-quality movies that are highly publicized. If quality differences are significant, the high-quality product will get the coordinated demand and in equilibrium we will not observe coordinating advertising.

\section{CONCLUDING REMARKS}

In markets with consumption externalities, firms might engage in advertising competition not only to inform the consumers, or to persuade them that one brand is somehow intrinsically different from other brands, but also to convince them that others will be buying it as well. It is plausible, for example, that the large advertising campaign for Windows 95 was not merely an attempt to inform consumers of the existence and price of the product, but it was also a device to coordinate consumer expectations on Windows 95.

The paper predicts that in markets with consumption externalities, when quality differences are not too great, consumers may often knowingly purchase the lower quality product. When Windows 95 and OS/2 were being introduced to the market, most of the software reviewers agreed that OS/2 was of slightly higher quality than Windows 95. However Microsoft managed to coordinate consumer expectations on Windows 95. IBM complained about having lost market share to Microsoft despite their higher quality. This paper suggests that OS/2 would have not lost the battle if it was of significantly superior quality. The quality difference between these products 
must have been small enough that consumers chose to enjoy consumption externalities at the cost of a slight decline in the product quality.

In the models of asymmetric information of Kihlstorm and Riordon (1984) and Ippolito (1990), the theoretically predicted correlation between quality and advertising is positive. In a repeat purchase framework, the firm with higher quality has higher incentives to advertise, since the potential buyer would engage in repeat purchase of the high-quality good. However, empirically Bagwell (2007) reports in his survey article that studies do not offer strong evidence for the hypothesis of a positive association between quality and advertising. We show that the theoretically predicted correlation between advertising and quality is weakly negative when advertising serves as a coordination device in markets with consumption externalities. The equilibrium of the advertising competition is in mixed strategies. While there will be times where the high-quality product has higher advertising, more frequently it will be the low-quality product that will capture the higher advertising position. 


\section{References}

Bagwell, K. (2007).“The Economic Analysis of Advertising," in Mark Armstrong and Rob Porter (eds.), Handbook of Industrial Organization, Vol. 3, North-Holland: Amsterdam, 2007, 1701-1844.

Bagwell, K. and G. Ramey (1994). "Coordination Economies, Advertising, and Search Behavior in Retail Markets", American Economic Review, Vol. 84, No. 3, pp. 489-517.

Baye, M., D. Kovenock and C. De Vries (1993). "Rigging the Lobbying Process: An Application of the All-Pay Auction", American Economic Review, Vol. 83, No. 1, pp.289-294.

(1996). "The All-Pay Auction with Complete Information", Economic Theory, Vol.8, No. 2, pp.291-305.

Becker, G. and K. Murphy (1993). "A Simple Theory of Advertising as a Good or Bad”, Quarterly Journal of Economics, Vol. 108, No. 4, pp. 941-964.

Butters, G. (1977). "Equilibrium Distribution of Prices and Advertising", Review of Economic Studies, Vol. 44, No. 3, pp. 465-492.

Clark, C. R. and I. J. Horstmann (2005). "Advertising and Coordination in Markets with Consumption Scale Effects", Journal of Economics and Management Strategy, Vol. 14, No. 2, pp. 377-402.

Dixit, A. and V. Norman (1978). "Advertising and Welfare", Bell Journal of Economics, Vol. 9, No. 1, pp. 1-17.

Ellingsen, T. (1991). "Strategic Buyers and the Social Cost of Monopoly", American Economic Review, Vol. 81, No. 3, pp. 648-656.

Hillman, A. L. And J. G. Riley (1989) "Politically Contestable Rents and Transfers", Economics and Politics, Vol.1, No. 1, pp.17-39.

Galbraith, J. K. (1967). The New Industrial State, Boston, Houghton Mifflin.

Grossman, G. and C. Shapiro (1984).“Informative Advertising with Differentiated Products", Review of Economic Studies, Vol. 51, No. 1, pp. 63-82.

Ippolito, P. M. (1990). "Bonding and Non-bonding Signals of Product Quality", Journal of Business, Vol. 63, No. 1, pp. 41-60

Kihlstrom, R. and M. Riordan (1984). “Advertising as a Signal”, Journal of Political Economy, Vol. 92, No. 3, pp. 427-450.

Meurer, M. and D. Stahl (1994). "Informative Advertising and Product Match", International Journal of Industrial Organization, Vol. 12, No. 1, pp. 1-19. 
Milgrom, P. and J. Roberts (1986). "Price and Advertising Signals of Product Quality", Journal of Political Economy, Vol. 94, No. 4, pp. 796-821.

Nelson, P. (1974). “Advertising as Information”, Journal of Political Economy, Vol. 82, No. 4, pp. $729-754$.

Panettieri, J. (1995). “Like a Gale Force”, Information Week, March 27, pp. 46-56.

Pastine, I. and T. Pastine (2002). "Consumption Externalities, Coordination and Advertising", International Economic Review, Vol. 43, No. 3, pp. 919-943.

Rebello, K. and M. Kuntz (1995). "Feel the Buzz: Win95's marketing blitz will be loud-and costly", Information Week, August 28 , pp. 31.

Reinstein, D. A. and C. M. Snyder (2005). "The Influence of Expert Reviews on Consumer Demand for Experience Goods: A Case Study of Movie Critics", Journal of Industrial Economics, Vol. 53, No. 1, pp. 27-51.

Robert, J. and D. Stahl (1993). "Informative Price Advertising in a Sequential Search Model", Econometrica, Vol. 61, No. 3, pp. 657-686.

Solow, R. (1967). “The New Industrial State or Son of Affluence”, Public Interest, Vol. 9, pp.100108 .

Stahl, D. (1994). “Oligopolistic Pricing and Advertising”, Journal of Economic Theory, Vol. 64, No. 1, pp. 162-177.

Stegeman, M. (1991). “Advertising in Competitive Markets”, American Economic Review, Vol. 81 , No. 1, pp. 210-223.

Tullock, G. (1980). "Efficient Rent Seeking”, in J. M. Buchanan, R. D. Tollison, and G. Tullock, eds., Toward a Theory of the Rent Seeking Society, College Station, Texas A\&M University Press, pp. 269-82. 